\title{
Improvement of Electric Discharge Machining (EDM) Performance of Ti-6Al-4V Alloy with Added Graphite Powder to Dielectric
}

\author{
Emre Unses ${ }^{1}$ - Can Cogun ${ }^{2}$ * \\ 1 TUBITAK Space Technologies Research Institute, Turkey \\ ${ }^{2}$ Cankaya University, Faculty of Engineering, Mechatronics Engineering Department, Turkey
}

Ti-6Al-4V is a well-known Ti alloy widely used in the aerospace industry and belongs to the group of difficult-to-machine materials. It is less suitable for both conventional chip removal (machining) techniques and electric discharge machining (EDM). The very low material removal rate (MRR) of the Ti alloys during the EDM process causes prohibitively long machining durations. The goal of this study was to improve the EDM performance of the Ti-6Al-4V alloy by the addition of graphite powder into the kerosene dielectric liquid. The EDM performance was quantified by MRR, tool electrode wear rate (EWR), relative wear (RW), surface roughness and texture properties. The experiments conducted have shown that the use of graphite powder mixed with the kerosene dielectric (GPMKD) during machining considerably increases the MRR, improves the $R_{a}$ and $R_{\mathrm{Z}(\mathrm{DIN})}$ surface roughness and decreases the RW. 3D topographic views of the machined workpiece surfaces attained with GPMKD revealed uniformly distributed surface valleys and peaks over the surface and peaks with short and round tops since the discharge energy of a spark is distributed over a large area at the machining gap. The experimental results strongly indicate the adaptability of the proposed technique to EDM die sinking and EDM drilling applications of the Ti-6Al-4V alloy in the aerospace industry. The ED machining performance of Ti-6Al-4V alloy using GPMKD is also compared to that of AISI 1040 steel, which is commonly used in EDM applications.

Key words: electric discharge machining (EDM), Ti-6Al-4V, graphite powder, material removal, tool electrode wear, roughness,

3D surface topography

Highlights

- The use of graphite powder mixed kerosene dielectric (GPMKD) in Ti-6Al-4V machining increases the material removal rate (MRR).

- $\quad$ GPMKD use resulted in lower peak-to-valley heights than the kerosene dielectric considering surface topographies.

- The machined surfaces were free of carbon contamination in the GPMKD experiments.

- Graphite powder used in this study is much cheaper than other metallic and non-metallic powders used in the literature.

\section{INTRODUCTION}

Electric discharge machining (EDM) is one of the non-traditional machining methods that is commonly used to produce die cavities by the erosive effect of electrical discharges. The success of EDM is associated with its capability of machining workpieces of high hardness and complex shapes that cannot be machined by conventional chip removal methods. This method is especially effective in machining hard die steels, complex cavities and small workpieces.

Ti-6Al-4V is a well-known Ti alloy widely used in the aerospace industry in jet engines, particularly in the disk and fan blade components of the compressor. Ti-6Al-4V has a 7 to 10 times higher electrical resistance, a 7 to 8 times lower heat conductivity and a $10 \%$ to $15 \%$ higher melting temperature than the AISI 1040 steel which is widely used in the production of machine elements and die applications. Ti-6Al-4V belongs to the group of difficult-to-cut materials in traditional machining. The two main problems in the traditional machining of Ti-6Al-4V are as follows: a) The heat generated during cutting action cannot be easily dissipated since Ti-6Al-4V is a poor heat conductor. The heat is concentrated on the cutting edge causing very short tool life.

b) The Ti-6Al-4V has a strong alloying tendency with cutting tool materials causing palling, welding and smearing on tool surface especially at high cutting temperatures.

For these reasons, cutting is performed at low cutting speeds to ensure a reasonable tool life. The economical machining rates of the Ti- $6 \mathrm{Al}-4 \mathrm{~V}$ vary between $20 \mathrm{~mm}^{3} / \mathrm{min}$ and $8000 \mathrm{~mm}^{3} / \mathrm{min}$ depending on machining operations, cutting tool characteristics, feed rates, cutting speeds and depth of cuts. The EDM of Ti alloys is also difficult as compared to $\mathrm{Ni}$ based super alloys due to high electrical resistivity (low electrical conductivity). During EDM of Ti-6Al-4V, a low level of current flows through the machining gap due to the high electrical resistance of the workpiece material [1]. Moreover, the locally increased temperature due to electrical discharges on the $\mathrm{Ti}$ alloy surface increases the electrical resistance of the 
material [2]. The low heat conductivity of the material also prevents the transfer of plasma channel heat to the work surface thus causing smaller surface craters. Both facts reduce the machinability and material removal rate (MRR) of the material significantly. Asokan et al. [1] used EDM for drilling holes in Ti-6Al-4V with a $\mathrm{Cu}$ tool electrode and deionized water dielectric. They concluded that the current, pulse time (pulse on time) $t_{s}$, pause time (pulse off time) $t_{p}$ and capacitance affected the MRR and the dimensional accuracy. Soni and Chakraverti [3] experimentally investigated the effects of discharge current $i_{d}$ and tool electrode rotational speed ( $0 \mathrm{rpm}$ to $1000 \mathrm{rpm}$ ) on MRR, tool electrode wear rate (EWR) and average surface roughness $\left(\mathrm{R}_{\mathrm{a}}\right)$ of the Ti alloy using commercial grade kerosene without a powder addition. They found that the increasing rotational speed of the $\mathrm{Cu}-\mathrm{W}$ tool electrode improved the MRR, but increased the EWR and $R_{a}$. Chen et al. [4] investigated the effects of deionized water and kerosene dielectric on machining performance of the Ti-6Al-4V alloy using a $\mathrm{Cu}$ tool electrode. The study revealed that the deionized water resulted in higher MRR and lower EWR than the kerosene. The lower MRR with the kerosene dielectric was attributed to: i) the formation of a TiC layer on the workpiece surface which has higher melting temperature than the workpiece material, ii) the formation of a $\mathrm{C}$ layer on the tool electrode surface causing passivation of electric discharge phenomena. Mhatre et al. [5] experimentally investigated the electric discharge drilling characteristics of Ti-6Al-4V using a commercial EDM dielectric IPOL. The $i_{d}$ is found to be the most significant parameter affecting the MRR, the dimensional accuracy and the surface integrity of the drilled hole. They also claimed that increasing the $i_{d}$ and the pulse voltage increases the MRR to a certain extent and decreases the EWR, while increasing $t_{s}$ causes a reduction in the EWR.

Numerous research studies have shown that using a powder mixed dielectric EDM (P-EDM) process can improve the surface roughness, increase MRR, and reduce EWR and relative wear (RW=EWR/ MRR). Addition of electrical conductive powder into the dielectric leads to a bridging effect and reduces the insulating strength of the dielectric fluid, thus forming a discharge channel more easily [3] and [6]. The bridging phenomena results in the multisplitting of one discharge occurrence over a larger area in the machining gap during a pulse cycle time. Thus, the energy of a pulse is shared across multiple discharges (with less energy), which form shallow and large diameter craters on the surface. These craters result in a better surface roughness and lower peak-to-valley heights in the machined surface profiles. In one of the earlier studies in the field, Jeswani [7] investigated the effects of adding $4 \mathrm{~g} / \mathrm{l}$ graphite powder into the kerosene dielectric during machining of mild steel with a copper tool electrode. An increase in MRR and a decrease in EWR and RW were reported. Uno and Okada [8] and Uno et al. [9] mixed Si and Ni powder into the dielectric to coat the Al-bronze die surface. The increasing Ni powder concentration $\left(C_{p}\right)$ resulted in smaller crater dimensions and a thicker re-solidified layer on the die surface alloyed with $\mathrm{Ni}$. They also obtained a hard TiC layer on the tool steel surface by using a Ti tool electrode and graphite mixed kerosene under reverse electrode polarity (to increase the wear of Ti tool electrode). Ming and He [10] stated that the addition of conductive and inorganic-oxide powders into kerosene decreases the ionization voltage of the dielectric and increases the machining gap. Cogun et al. [11] experimentally studied the effects of adding graphite and non-conductive boric acid powder into kerosene on MRR, EWR, RW, $\mathrm{R}_{\mathrm{a}}$ and surface hardness for the $\mathrm{Cu}$ tool electrode-steel workpiece pair. The graphite powder $C_{p}$ and the $t_{s}$ were the two machining parameters found to strongly effect MRR and EWR. Furutani et al. [12] mixed Ti powder into the dielectric to form a thick TiC layer on metal surfaces using small $\mathrm{Cu}$ wire or rotating disc electrodes. They realized that the higher Ti powder $C_{p}$ resulted in harder TiC coatings. In Prihandana et al. [13], the silver-tungsten workpiece was micro-drilled (holes with $300 \mu \mathrm{m}$ and $500 \mu \mathrm{m}$ depth) with a tungsten tool electrode at $10 \mathrm{~g} / 1$ graphite powder $C_{p}$ in the kerosene. They reported a five times higher MRR than for pure kerosene. Reddy et al. [14] investigated the machining characteristics of a PH17-4 stainless steel workpiece using surfactant (non-ionic SPAN20) and graphite mixed commercial EDM oil. They claimed an increase in electric conductivity of the dielectric fluid with increasing concentration of the surfactant. The maximum MRR has been achieved at $6 \mathrm{~g} / 1$ surfactant and $4.5 \mathrm{~g} / \mathrm{l}$ graphite powder concentration settings.

The literature survey reveals that little work has been carried out on the P-EDM of Ti-6Al-4V alloy. Lin et al. [15] used a hybrid process (EDM+USM (ultrasonic machining)) to machine the Ti-6Al-4V. The $\mathrm{SiC}$ powder added to deionized water and kerosene was used as a conductive powder in the dielectric for EDM and as an abrasive for the USM process. It is reported that increasing the $\mathrm{SiC}$ powder concentration up to $90 \mathrm{~g} / 1$ improved the MRR significantly. On the other hand, a very high $C_{p}$ resulted in the accumulation of excessive powder in the machining gap resulting in frequent arc pulses (undesirable) and low MRR. 
The kerosene with $\mathrm{SiC}$ powder led to better surface roughness than the deionized water with $\mathrm{SiC}$ powder. Chow et al. [16] investigated the effects of $\mathrm{Al}$ and $\mathrm{SiC}$ powder additions to the kerosene dielectric on MRR, EWR, $R_{a}$ and discharge voltage waveforms of the Ti$6 \mathrm{Al}-4 \mathrm{~V}$ workpiece. It is reported that the MRR was increased and $R_{a}$ was decreased for P-EDM cases. It was found that the $\mathrm{SiC}$ powder mixed kerosene resulted in a higher MRR than that of $\mathrm{Al}$ powder, whereas the lowest $R_{a}$ was experienced in $A l$ powder mixed cases. In another work of Chow et al. [17], the MRR and EWR performance of Ti-6Al-4V were tested for the deionized water dielectric with and without $\mathrm{SiC}$ powder addition by using a rotational copper disk tool electrode. The highest MRR and the lowest EWR were obtained when $25 \mathrm{~g} / 1 \mathrm{SiC}$ powder is mixed with deionized water. However, better $\mathrm{R}_{\mathrm{a}}$ and surface texture were reported for the $\mathrm{SiC}$ powder mixed cases compared to using the pure deionized water. Rival [18] experimentally investigated the effects of $\mathrm{SiC}$ powder addition $(2 \mathrm{~g} / \mathrm{l}$ to $6 \mathrm{~g} / \mathrm{l})$ into kerosene on MRR, EWR and $\mathrm{R}_{\mathrm{a}}$ for a Ti-6Al-4V workpiece and $\mathrm{Cu}-\mathrm{W}$ tool electrode. He found that the MRR and $R_{a}$ values were higher with higher $i_{d}$ for the powder mixed kerosene experiments. The lowest $\mathrm{R}_{\mathrm{a}}$ was obtained at $2 \mathrm{~g} / \mathrm{l} \mathrm{SiC}$ powder concentration. In Yasar and Ekmekci [19], the effects on surface topography of the Ti-6Al$4 \mathrm{~V}$ workpiece were investigated when $\mathrm{SiC}$ powder was added into deionized water and kerosene. In their experimental work, the $\mathrm{SiC}$ powder $C_{p}$, the powder particle size, $t_{s}$ and $i_{d}$ were determined as the key parameters affecting surface topography. Homogenous surface topographies with small surface craters were observed on workpiece surfaces machined with $\mathrm{SiC}$ added dielectrics.

\section{PURPOSE OF THE STUDY}

The literature survey revealed that a P-EDM study on the effect of a graphite powder mixed dielectric on machining performance of Ti-6Al-4V, an alloy seeing growing use in the aerospace industry, has not been reported on so far. The authors of this work believe from their past experience [11] that adding graphite powder to the dielectric can significantly improve specific machining performance outputs of Ti-6Al-4V alloy such as MRR, EWR, RW and surface roughness. Moreover, the proposed graphite powder in this study is $\sim 70 \%$ cheaper than the cheapest metallic and nonmetallic powders used in the literature (like $\mathrm{SiC}, \mathrm{Al}$, $\mathrm{Ni}$ ). This makes the graphite powder economically attractive with respect to the others. Moreover, the lower density of the graphite powder $\left(2.1 \mathrm{~g} / \mathrm{cm}^{3}\right)$ than the other powders $\left(\rho_{\mathrm{SiC}}=3.2 \mathrm{~g} / \mathrm{cm}^{3}, \rho_{\mathrm{Ni}}=8.9 \mathrm{~g} / \mathrm{cm}^{3}\right.$, $\rho_{\mathrm{Al}}=2.7 \mathrm{~g} / \mathrm{cm}^{3}$ ) makes the formation of a homogenous suspension of the powder in the dielectric easier (due to the same particle size distributions). Following these considerations, we study the effects of adding graphite powder to kerosene on the MRR, EWR, RW and machined workpiece surface characteristics $\left(\left(\mathrm{R}_{\mathrm{a}}\right.\right.$, $\mathrm{R}_{\mathrm{Z}(\mathrm{DIN})}$ and surface topography) depending on $t_{s}, i_{d}$ and the dielectric flushing pressure $P_{d}$.

\section{EXPERIMENTAL SETUP AND METHODS}

The electric discharge machine used in this investigation is FURKAN EDM M25 Model die sinking machine with EDM25A generator. The pulse generator is an iso-pulse type with $80 \mathrm{~V}$ open circuit voltage.

In the first group of experiments, the kerosene (KD) was used. In the second group of experiments, graphite powder smaller than $37 \mu \mathrm{m}$ particle size was mixed into kerosene (graphite powder mixed kerosene dielectric, GPMKD). Both the KD and the GPMKD experiments were conducted in a self-made machining tank with $40 \mathrm{~cm} \times 55 \mathrm{~cm} \times 24 \mathrm{~cm}$ dimensions made of $1.5 \mathrm{~mm}$ thick stainless steel sheets (Fig. 1). In order to maintain a homogenous suspension of graphite powder in the tank during tests, a flush mixing was applied by means of two parallel spaced (at the two bottom sides of the tank) $12 \mathrm{~mm}$ diameter $\mathrm{Cu}$ pipes with $2.4 \mathrm{~mm}$ diameter holes on it. The dielectric was sucked from the bottom level of the tank by means of a pump. One of the two branches of the pump exit was directed to the $\mathrm{Cu}$ pipes for homogenous mixing of the powder. The other branch was directed towards the machining gap (side flushing) for flushing the machining debris away. A manometer and an adjustment vane were mounted to the flushing branch to set the flushing pressure.

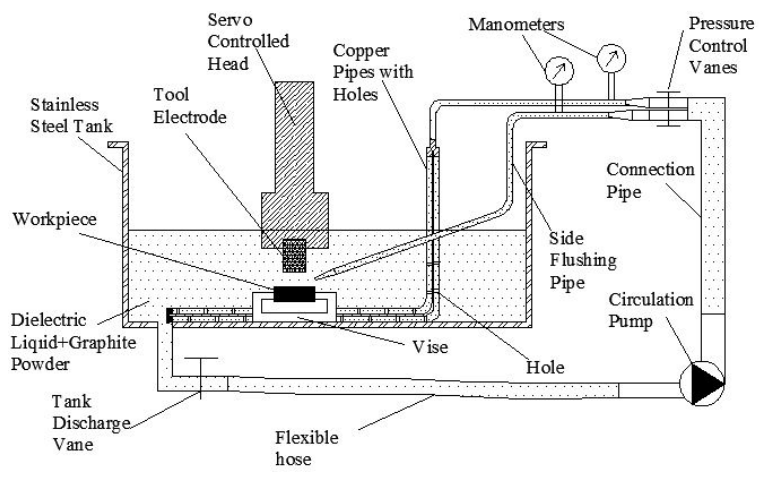

Fig. 1. Experimental setup 
The graphite powder $C_{p}$ to be used in the experiments was determined by a set of experiments conducted at $t_{s}=100 \mu \mathrm{s}, i_{d}=12 \mathrm{~A}, P_{d}=0.1$ bar (Exp. 13) machining settings for $C_{p}$ at $1 \mathrm{~g} / 1,3 \mathrm{~g} / 1,5 \mathrm{~g} / \mathrm{l}$, $10 \mathrm{~g} / 1$ and $15 \mathrm{~g} / \mathrm{l}$. The machining duration was 70 minutes. Compared to the KD experiments (Fig. $2 \mathrm{a}$ and $\mathrm{b}$ ), negligibly slight deviations in MRR and EWR values were observed at both $1 \mathrm{~g} / 1$ and $3 \mathrm{~g} / 1 C_{p}$ values. At $C_{p}=5 \mathrm{~g} / 1$, the MRR is almost doubled with respect to the KD. A very slight increase in MRR was observed at $C_{p}=10 \mathrm{~g} / 1$ and $C_{p}=15 \mathrm{~g} / 1$ (Fig. 2a) with respect to $C_{p}=5 \mathrm{~g} / \mathrm{l}$. No significant difference in EWR values between $\mathrm{KD}$ and GPMKD with $C_{p}=5 \mathrm{~g} / 1$ was observed. However, the EWR increased noticeably for $C_{p}=10 \mathrm{~g} / 1$ and $C_{p}=15 \mathrm{~g} / 1$ (Fig. 2b). The $\mathrm{R}_{\mathrm{a}}$ value was decreased with increasing $C_{p}$ up to the $5 \mathrm{~g} / \mathrm{l}$ level and no further improvement was observed above this particular level (Fig. 2c). Thus, $C_{p}=5 \mathrm{~g} / 1$ was selected as the level giving the best machining performance outputs among the tested $C_{p}$ levels. In the literature, the elevated MRR values of various grades of steel and silver-tungsten workpieces with a range of 4 $\mathrm{g} / 1$ to10 $\mathrm{g} / 1$ graphite powder $C_{p}$ in the kerosene [7], [11] and [13] and at $4.5 \mathrm{~g} / \mathrm{l}$ graphite powder $+6 \mathrm{~g} / \mathrm{l}$ surfactant concentration in the EDM oil [14] were also reported.
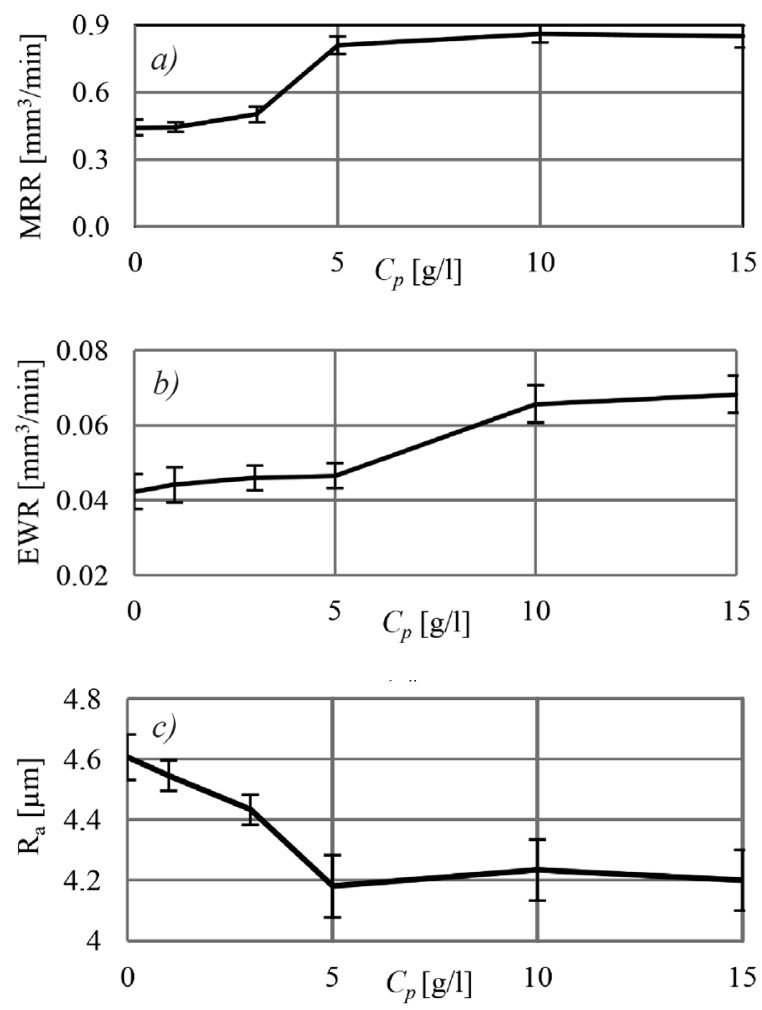

Fig. 2. The effect of $C_{p}$ on: a) MRR, b) EWR and c) $R_{a}$
In the experiments, the workpiece material used was a Ti-6Al-4V Grade 5 alloy ( $90 \%$ Ti, 5.9\% Al, 4\% Va, $0.07 \% \mathrm{Fe}, 0.02 \% \mathrm{C}$ ). The physical, mechanical, electrical and thermal properties of the alloy are given in Table 1. The workpieces were cut from a $30 \mathrm{~mm}$ diameter bar at $6 \mathrm{~mm}$ lengths. The bottom and top circular surfaces were finished using a fine emery paper. The workpieces were cut-off at their plane of symmetry to form two identical halves (Fig. 3). The two halves were contacted to each other to form a solid workpiece during experiments by using a simple vise. At the end of the machining, the separated halves facilitated easy surface roughness measurement since the mechanical contact stylus of the device should move along (traverse) the ED machined surface in horizontal. The same size of AISI 1040 steel $(0.38 \% \mathrm{C}, 0.6 \% \mathrm{Mn}, 0.04 \% \mathrm{P}, 0.05 \% \mathrm{~S})$ workpieces (properties given in Table 1) were also prepared and ED machined to compare the MRR, EWR, $R_{a}$ and RW values with that of Ti-6Al-4V. The electrolytic copper tool electrodes used in the experiments were in a cylindrical shape cut from a $14 \mathrm{~mm}$ diameter copper bar. The tool electrodes were $13 \mathrm{~mm}$ in diameter and $40 \mathrm{~mm}$ in length.

Table 1. Properties of the Ti-6Al-4V alloy and the AISI 1040 steel

\begin{tabular}{lcc}
\hline Properties & Ti-6Al-4V [20] & AISI 1040 \\
\hline Density [g/cm 3 ] & 4.43 & 7.85 \\
\hline Brinell hardness [-] & 334 & 163 \\
\hline Yield/ UT Strength [MPa] & $1040 / 1080$ & $361 / 585$ \\
\hline Elasticity module [GPa] & 113.8 & 200 \\
\hline Poisson ratio [-] & 0.34 & 0.31 \\
\hline Electrical resistance $[\Omega \cdot \mathrm{cm}]$ & $178 \mathrm{e}^{-6}$ & $171 \mathrm{e}^{-7}$ \\
\hline Spec. heat capacity $[\mathrm{J} /(\mathrm{kg} \cdot \mathrm{K})]$ & 526 & 486 \\
\hline Heat conductivity $[\mathrm{W} /(\mathrm{m} \cdot \mathrm{K})]$ & 6.7 & 50.7 \\
\hline Melting point $\left[{ }^{\circ} \mathrm{C}\right]$ & 1604 to 1660 & 1400 to 1450 \\
\hline
\end{tabular}

In this study, the preliminary experiments with $t_{s}$ and $i_{d}$ values lower than $50 \mu$ and $6 \mathrm{~A}$, respectively, indicated prohibitively long machining cycles. On the other hand, extremely poor surface roughness prevented us from using $t_{s}$ and $i_{d}$ values above $100 \mu \mathrm{s}$ and $12 \mathrm{~A}$, respectively. In the experiments, a long $t_{p}(100 \mu \mathrm{s})$ was selected to allow more time for the removal of heat from the machining medium both via dielectric circulation (convective heat transfer) [21] and conductive heat transfer. The machining parameters and experimental design are given in Tables 2 and 3. Every experiment was repeated three times and the average of the measurements was used in the analysis. Error bars were also added to the graphical representation of the results to depict the 
fluctuations in the measurements. Weight loss of the tool electrodes and workpieces were determined by taking initial and final (after machining) weights of the tool electrodes and workpieces using a HANA HG-1 type digital scale with $0.005 \mathrm{~g}$ accuracy. The weight losses were used to calculate the MRR, EWR and RW. Workpiece $\mathrm{R}_{\mathrm{a}}$ and $\mathrm{R}_{\mathrm{Z(DIN})}$ (average of the highest peak-to-valley measurements found for each cut-off length) measurements were performed using a portable Rank Taylor-Hobson Surtronic 3+ HB103 stylus tracing instrument. The average of the measurements taken at six locations was used in the analysis.

The experiments were intentionally carried out using the arc control mode of the pulse generator at "medium suppression" level to observe the effects of machining parameters $\left(i_{d}, t_{s}, P_{d}\right)$ and GPMKD on machining stability (regime). This setting level doesn't completely prevent the formation of arcs. However, we retracted the tool electrode in a timely manner (Table 2) to reduce the risk of tool electrode and workpiece surface damage due to arcing.

$3 \mathrm{D}$ topographic views of the machined workpiece surfaces were generated by using a photometric stereo technique. A Point Grey Dragon Fly camera was used as the photographic capture system. The $2 \mathrm{~mm} \times 2 \mathrm{~mm}$ surfaces were selected from the machined workpiece to obtain the topographic views. The $0.5 \mathrm{~mm} \times 0.5$ $\mathrm{mm}$ areas on the $2 \mathrm{~mm} \times 2 \mathrm{~mm}$ views were magnified for closer examination of the surface characteristics. A Mitutoya MF176 toolmakers microscope was also used to examine the formed surface craters' characteristics.

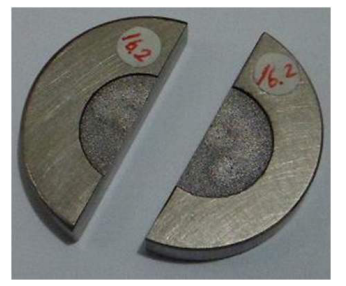

Fig. 3. A machined Ti-6Al-4V workpiece

\section{EXPERIMENTAL RESULTS AND DISCUSSION}

\subsection{Effect of GPMKD on MRR}

The MRR increased with increasing $t_{s}$ and $P_{d}$ for both KD and GPMKD experiments (Fig. 4). The longer $t_{s}$ resulted in a higher amount of energy transfer to the workpiece surface leading to higher amounts of work material removal by melting and evaporation phenomena [11]. For all machining settings, the MRR was increased by the use of GPMKD (Fig. 4), which was attributed to the following factors:

a) GPMKD reduces the electric resistance of the machining gap enabling high current (energy) flow through the gap and high amount of material removal from the workpiece craters [6].

b) The GPMKD widens the gap eliminating the difficulties in dielectric circulation and removal of debris in the machining medium, which in turn results in a higher number effective discharges [21] leading to higher MRR.

The second factor is more dominant in increasing MRR since Ti-6Al-4V has an extremely low thermal conductivity (proportional to the electrical conductivity) causing only small workpiece craters.

In this study, a $25 \%$ to $104.3 \%$ increase in Ti6Al-4V MRR is achieved by using GPMKD for the machining settings used. In the literature, a $60 \%$ to $500 \%$ increase in MRR of non-Ti alloy workpieces (such as mild steel, 1040 steel and stainless steel) was reported when using GPMKD [7], [11] and [13]. Yet, only a $28.5 \%$ to $60 \%$ increase in Ti-6Al-4V MRR using $\mathrm{Al}$ or $\mathrm{SiC}$ powder mixed kerosene or deionized water was reported [15] to [17]. Therefore, the addition of graphite powder into kerosene resulted in a higher Ti-6Al-4V MRR than the addition of $\mathrm{Al}$ and $\mathrm{SiC}$ powders into the dielectrics.

Table 2. Experimental settings

\begin{tabular}{lc}
\hline Machining Parameter & Setting \\
\hline Discharge current, $i_{d}[\mathrm{~A}]$ & 6,12 \\
\hline Pulse (on) time, $t_{s}[\mu \mathrm{s}]$ & 50,100 \\
\hline Pause (pulse-off) time, $\mathrm{t}_{\mathrm{p}}[\mu \mathrm{s}]$ & 100 \\
\hline Work duration $[\mathrm{s}]$ & 1.6 \\
\hline Retraction duration $[\mathrm{s}]$ & 0.8 \\
\hline Dielectric pressure, $P_{d}[\mathrm{bar}]$ & $0.1,0.4$ \\
\hline Dielectric liquid & $\mathrm{KD}, \mathrm{GPMKD}$ \\
\hline Dielectric flushing type & side \\
\hline Polarity & tool electrode $(+)$ \\
\hline Machining depth $[\mathrm{mm}]$ & 0.7 \\
\hline
\end{tabular}

\subsection{Effect of GPMKD on Surface Roughness and Topography}

Referring to Fig. 5, an increase in $P_{d}$ does not lead to a significant difference in the values of $R_{a}$ when comparing the KD and GPMKD experiments. It can also be seen that varying $t_{s}$ has a smaller effect on $\mathrm{R}_{\mathrm{a}}$ in the KD experiments. The higher $P_{d}$ yielded a stable machining regime and less carbon accumulation on the surface. Destruction of the workpiece and tool electrode surface was observed in the KD experiments 
when improper $t_{s}$ and $t_{p}$ values were selected for the used $i_{d}$ values. The typical type of destruction was the lamination of the $\mathrm{Cu}$ tool electrode due to high temperatures generated in the gap, since $\mathrm{Cu}$ has lower melting temperature than the Ti-6Al-4V.

Table 3. Experimental design

\begin{tabular}{ccccc}
\hline Exp. no & Dielectric & $t_{s}[\mu \mathrm{s}]$ & $i_{d}[\mathrm{~A}]$ & $P_{d}[\mathrm{bar}]$ \\
\hline 1 & $\mathrm{KD}$ & 50 & 12 & 0.1 \\
\hline 2 & $\mathrm{KD}$ & 50 & 12 & 0.4 \\
\hline 3 & $\mathrm{KD}$ & 50 & 6 & 0.1 \\
\hline 4 & $\mathrm{KD}$ & 50 & 6 & 0.4 \\
\hline 5 & $\mathrm{KD}$ & 100 & 12 & 0.1 \\
\hline 6 & $\mathrm{KD}$ & 100 & 12 & 0.4 \\
\hline 7 & $\mathrm{KD}$ & 100 & 6 & 0.1 \\
\hline 8 & $\mathrm{KD}$ & 100 & 6 & 0.4 \\
\hline 9 & GPMKD & 50 & 12 & 0.1 \\
\hline 10 & GPMKD & 50 & 12 & 0.4 \\
\hline 11 & GPMKD & 50 & 6 & 0.1 \\
\hline 12 & GPMKD & 50 & 6 & 0.4 \\
\hline 13 & GPMKD & 100 & 12 & 0.1 \\
\hline 14 & GPMKD & 100 & 12 & 0.4 \\
\hline 15 & GPMKD & 100 & 6 & 0.1 \\
\hline 16 & GPMKD & 100 & 6 & 0.4 \\
\hline
\end{tabular}

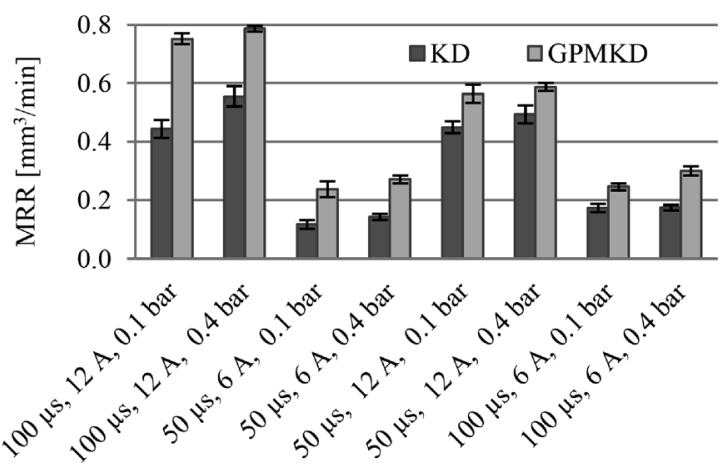

Fig. 4. Effect of GPMKD on MRR

The high temperature in the gap was due to poor heat conductivity of the Ti-6Al-4V workpiece [1]. The laminated tool electrode surface also causes deterioration of the workpiece surface. Accordingly, the GPMKD experiments resulted in lower $R_{a}$ values (Fig. 5) and shinier surfaces compared to the KD experiments. The main reasons for this result are the enlarged heat discharge area forming large diameter and shallow craters [6], [11] and [16] and the accumulation of less carbon black (due to less frequent arc formations) on the surface.

In this study, a $2.4 \%$ to $18.3 \%$ decrease in $\mathrm{R}_{\mathrm{a}}$ is observed by using GPMKD for the machining settings used. In the literature, a $5.4 \%$ to $67 \%$ decrease in
$\mathrm{R}_{\mathrm{a}}$ in machining of the 1040 steel workpiece by using GPMKD was reported [11]. However, $\mathrm{R}_{\mathrm{a}}$ decreases of at most $25 \%$ [15], $30.5 \%$ [16], $35 \%$ [17] and $27 \%$ [18] have been reported in the machining of Ti-6Al$4 \mathrm{~V}$ with kerosene $+\mathrm{SiC}$ powder, kerosene $+\mathrm{Al}$ powder, deionized water $+\mathrm{SiC}$ powder and kerosene $+\mathrm{SiC}$ powder mixtures, respectively. So, the $R_{a}$ values measured in this study (3.8 $\mathrm{mm}$ to $4.7 \mathrm{~mm}$ ) in the machining of Ti-6Al-4V with GPMKD are consistent with the reported findings in the literature $(2.5 \mathrm{~mm}$ to $3.6 \mathrm{~mm}$ ) for the same workpiece but for different dielectric and powder mixture combinations.

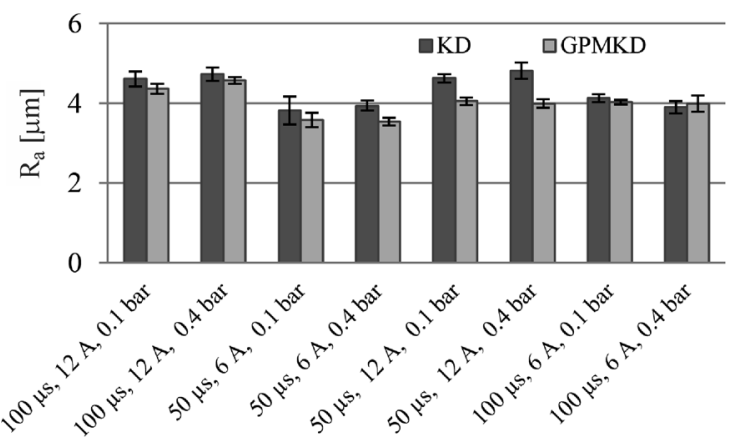

Fig. 5. Effect of GPMKD on $\mathrm{R}_{\mathrm{a}}$

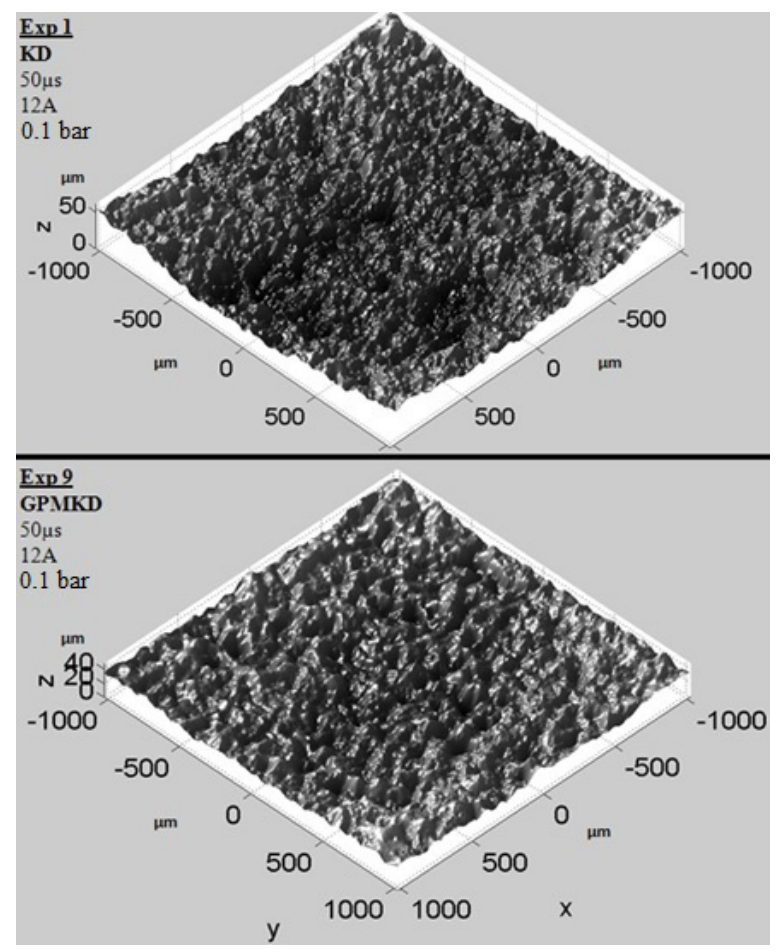

Fig. 6. The 3D topographic views of the workpiece surfaces (Exp. 1 and 9)

The average workpiece surface peak-to-valley heights of the KD experiments $(\sim 50 \mu \mathrm{m}$ in Exp. 1 (Fig. 
6a)) were decreased in GPMKD cases $(\sim 40 \mu \mathrm{m}$ in Exp. 9 (Fig. 6b)). Uneven distribution of peaks and valleys was also observed in $\mathrm{KD}$ experiments due to frequent occurrences of undesirable arcs at the same spot. Magnified surface topography photographs revealed uniformly distributed short and round top peaks due to the uniform distribution of discharge energy in the gap in the GPMKD experiments. The surface topographies shown in Fig. 7 were formed by half of the energy discharges of Fig. 6 resulting in smaller craters and shorter peaks. In the GPMKD experiments, the $\mathrm{z}$ axis average height is decreased from $\sim 40 \mu \mathrm{m}$ to $\sim 20 \mu \mathrm{m}$ with respect to $\mathrm{KD}$ experiments. Roughness measurements revealed $4.8 \%$ to $13.4 \%$ reduction in $\mathrm{R}_{\mathrm{Z} \text { (DIN) }}$ values in GPMKD cases (Table 4). This reduction also verified the formation of shorter peaks (smaller peak-to-valley heights) through the use of the GPMKD.

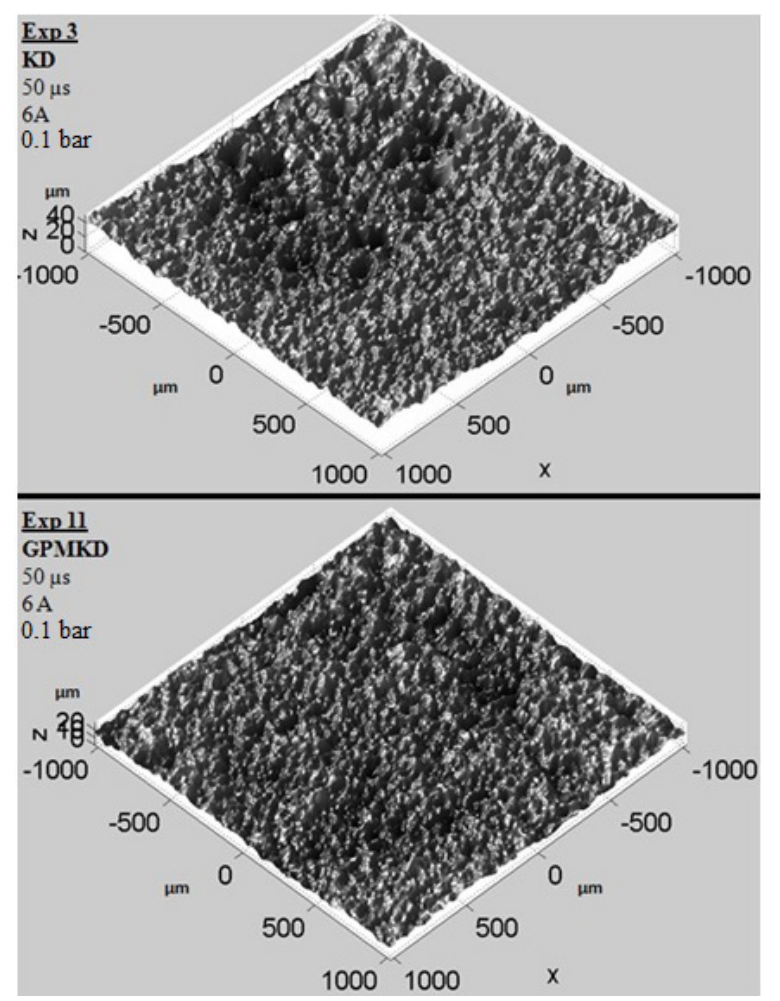

Fig. 7. The 3D topographic views of the workpiece surfaces (Exp. 3 and 11)

Table 4. $\mathrm{R}_{\mathrm{z}(\mathrm{DIN})}$ measurements

\begin{tabular}{|c|c|c|c|c|}
\hline \multicolumn{2}{|c|}{$\mathrm{KD}$} & \multicolumn{2}{|c|}{ GPMKD } & \multirow{2}{*}{ Diff. [\%] } \\
\hline Exp. no & $\mathrm{R}_{\mathrm{Z}(\mathrm{DIN})}[\mu \mathrm{m}]$ & Exp. no & $\mathrm{R}_{\mathrm{Z}(\mathrm{DIN})}[\mu \mathrm{m}]$ & \\
\hline 1 & 23.4 & 9 & 21.2 & 9.4 \\
\hline 3 & 23.0 & 11 & 19.9 & 13.4 \\
\hline 5 & 24.8 & 13 & 22.5 & 9.2 \\
\hline 6 & 25.2 & 14 & 24.0 & 4.8 \\
\hline
\end{tabular}

\subsection{Effect of GPMKD on EWR and RW}

Although it can be observed that EWR and RW increased with increasing values of $P_{d}$ for both KD and GPMKD experiments, the EWR and RW values show significant variations depending on the values of $t_{s}$ and $i_{d}$. The EWR and RW were decreased noticeably with increasing $t_{s}$ (Figs. 8 and 9). The decrease in RW with increasing $t_{s}$ was an expected result since the MRR increases and EWR decreases with increasing $t_{s}$. It was found that the $i_{d}$ was the most significant machining parameter affecting machining performance outputs of Ti-6Al-4V. At high $i_{d}$ settings, more electric current (energy) passing through the gap results in a large amount of workpiece and electrode material removal by melting and evaporation [11] and [22]. Due to this fact, the increased $i_{d}$ resulted in higher $\mathrm{R}_{\mathrm{a}}$ (Fig. 5), EWR (Fig. 8) and RW (Fig. 9).

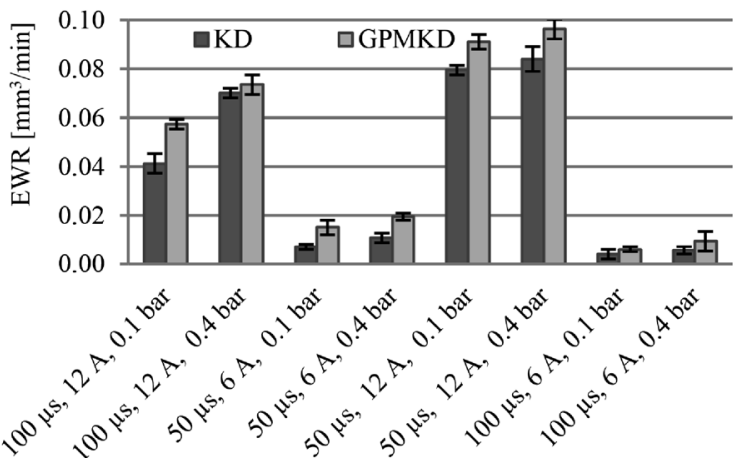

Fig. 8. Effect of GPMKD on EWR

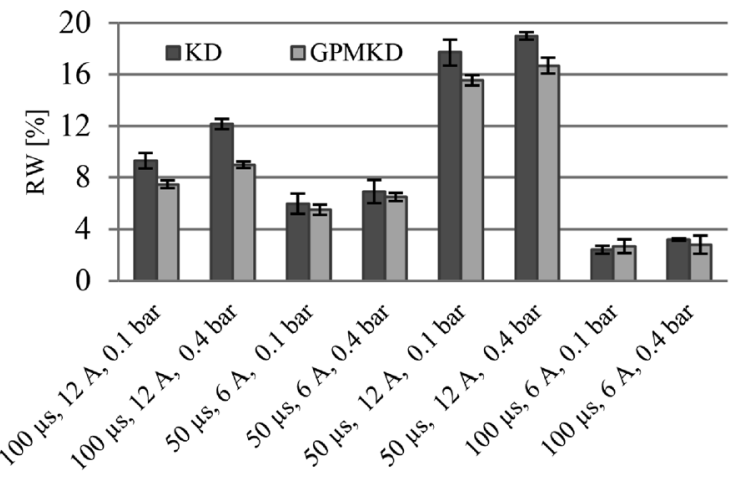

Fig. 9. Effect of GPMKD on RW

Slight increases in the EWR values were observed in the GPMKD compared to KD experiments (Fig. 8 ). This was attributed to big crater formations with the increasing electrical conductivity of the dielectric liquid in the GPMKD cases. In this study, a $4 \%$ to 72 $\%$ increase in EWR was observed by using GPMKD for the tested machining settings. In machining of 
Ti-6Al-4V with $\mathrm{Al}$ or $\mathrm{SiC}$ powder mixed kerosene or deionized water, a $150 \%$ to $200 \%$ [16], $57 \%$ [17] and $105 \%$ to $175 \%$ [18] increase in EWR have been reported. Therefore, the increase in EWR observed in this study could be considered to be in reasonable agreement with other studies. On the other hand, a $15 \%$ decrease in EWR was reported in machining of a mild steel workpiece with GPMKD at a low pulse discharge energy [7].

Fig. 9 clearly highlights the contribution of GPMKD use on the reduction of RW (7.7 \% to $26 \%$ ). This is an important measure of long tool electrode life and economical machining.

\subsection{Comparison of ED Machinability of AISI 1040 and Ti 6Al-4V Workpieces}

The MRR of Ti-6Al-4V was 14.9 to 18.6 times slower than that of AISI 1040 for the KD experiments. Although the MRR was improved greatly by GPMKD use, the MRR of Ti-6Al-4V was still 11.9 to 13 times slower than that of AISI 1040 (Fig. 10). The RW values obtained in Ti-6Al-4V were 0.4 to 2.4 times higher than AISI 1040 in KD experiments. The GPMKD use reduced these values by $\sim 20 \%$ (Fig. 11). The lower electrical resistance and higher heat conductivity of the AISI 1040 than the Ti-6Al-4V led to larger diameter and deeper crater formations (evident from microscopic examinations) causing higher $\mathrm{R}_{\mathrm{a}}$ values (Fig. 12).

\section{CONCLUSION}

This study is the first significant effort to use a graphite powder mixed dielectric to improve ED machining performance of the Ti-6Al-4V alloy in an EDM die sinking operation. The experimental results allow us to draw the following conclusions:

1) The increasing dielectric flushing pressure $\left(P_{d}\right)$ improved the MRR significantly and increased the tool electrode wear rate (EWR) slightly for both the kerosene dielectric (KD) and the graphite powder mixed kerosene dielectric GPMKD cases. The $\mathrm{R}_{\mathrm{a}}$ wasn't affected noticeably by the variation in $P_{d}$. Increasing $t_{s}$ increased the MRR and decreased the EWR for KD and GPMKD. No changes in $\mathrm{R}_{\mathrm{a}}$ were observed with the variation in $t_{s}$.

2) The machining was very stable and machined surfaces were free of carbon contamination in the GPMKD experiments, especially at high $P_{d}$ settings.

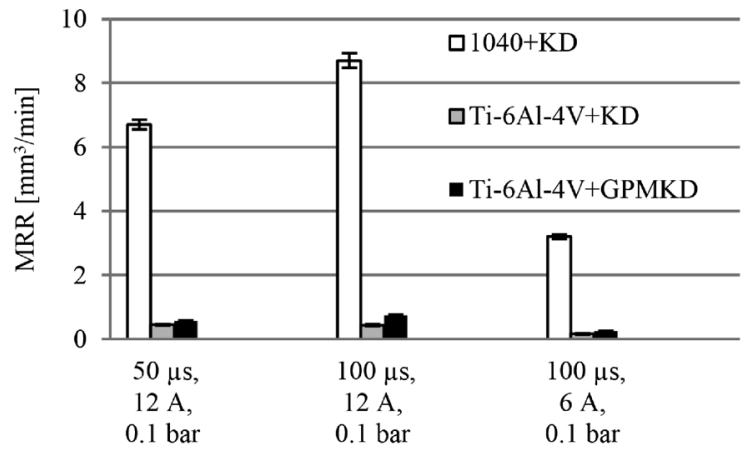

Fig. 10. Comparison of MRR values of AISI 1040 and Ti-6Al-4V

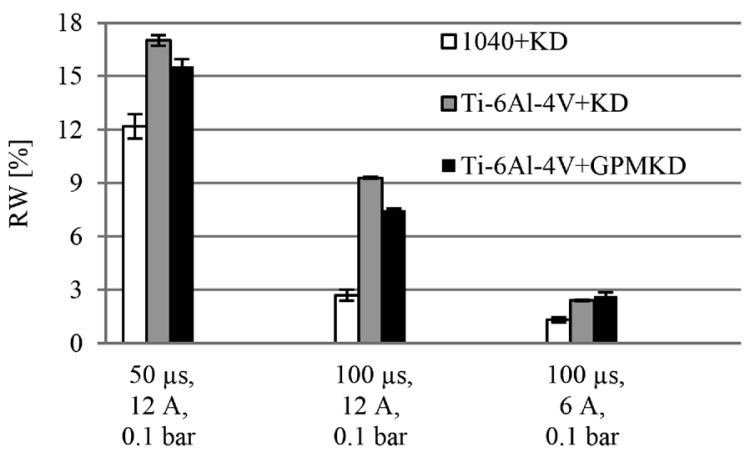

Fig. 11. Comparison of RW values of AISI 1040 and Ti-6Al-4V

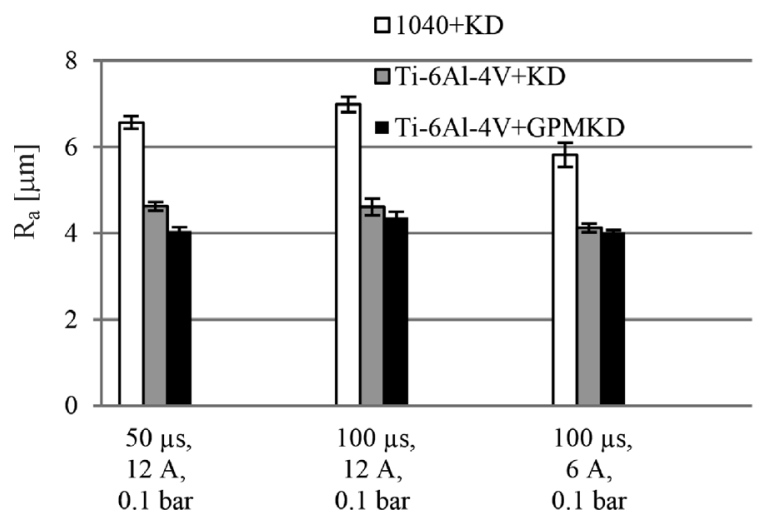

Fig. 12. Comparison of $R_{a}$ values of AISI 1040 and Ti-6Al-4V

3) The GPMKD improved the MRR, $R_{a}$ and RW of Ti-6Al-4V workpiece. The 3D surface topography of the machined surfaces revealed that the GPMKD use resulted in lower peak-tovalley heights than the KD experiments.

4) Although the use of GPMKD improved the MRR of the Ti-6Al-4V significantly, the MRR values with respect to the AISI 1040 steel workpiece were still low. However, much better $\mathrm{R}_{\mathrm{a}}$ values in Ti-6Al-4V than in AISI 1040 were obtained with the use of KD and GPMKD. 
Graphite powder is at least $70 \%$ cheaper than other metallic and non-metallic powders used in the literature and is, thus, economically highly attractive. Moreover, the lower density of the graphite powder than the other powders provides a more homogenous suspension of the powder, which provides a stable ED machining regime. We also emphasize that the proposed graphite powder addition to the dielectric can be readily adapted to EDM die sinking and EDM drilling applications of Ti-6Al-4V in the aerospace industry considering the observed improvements in machining performance and lower costs.

\section{NOMENCLATURE}

MRR Material removal rate $\left[\mathrm{mm}^{3} / \mathrm{min}\right]$

EWR Tool electrode wear rate $\left[\mathrm{mm}^{3} / \mathrm{min}\right]$

RW Relative wear (EWR/MRR) [\%]

$\mathrm{R}_{\mathrm{a}} \quad$ Average surface roughness $[\mu \mathrm{m}]$

$R_{z(\text { DIN })}$ Average of the highest peak to valley measurements found for each cut-off length $[\mu \mathrm{m}]$

$t_{s} \quad$ Pulse time (pulse on time) $[\mu \mathrm{s}]$

$t_{p} \quad$ Pause time (pulse off time) $[\mu \mathrm{s}]$

$i_{d} \quad$ Discharge current $[\mathrm{A}]$

$C_{p} \quad$ Powder concentration $[\mathrm{g} / \mathrm{l}]$

$P_{d} \quad$ Dielectric flushing pressure [bar]

\section{REFERENCES}

[1] Asokan, T., Sudhakar, R.S., De Costa, P. (2000). Electrical discharge drilling of titanium alloys for aerospace applications. Proceedings of the 19th AIMTDR Conference, p. 161-165.

[2] Zhang, W.J., Reddy, B.V., Deevi, S.C. (2001). Physical properties of TiAl-base alloys. Scripta Materialia, vol. 45, no. 6, p. 645-651, D0I:10.1016/S1359-6462(01)01075-2.

[3] Soni, J.S., Chakraverti, G. (1994). Machining characteristics of titanium with rotary electro-discharge machining. Wear, vol. 171, no. 1-2, p. 51-58, Dol:10.1016/0043-1648(94)90347-6.

[4] Chen, S.L., Yan, B.H., Huang F.Y. (1999). Influence of kerosene and distilled water as dielectrics on the electric discharge machining characteristics of Ti-6Al-4V. Journal of Materials Processing Technology, vol. 87, no. 1-3, p. 107-111, DOI:10.1016/S0924-0136(98)00340-9.

[5] Mhatre, M.S., Sapkal, S.U., Pawade, R.S. (2014). Electro discharge machining characteristics of Ti-6Al-4V alloy: A grey relational optimization. Procedia Materials Science, vol. 5, p. 2014-2022, D0I:10.1016/j.mspro.2014.07.534.

[6] Zhao, W.S., Meng, Q.G., Wang, Z.L. (2002). The application of research on powder mixed EDM in rough machining. Journal of Materials Processing Technology, vol. 129, no. 1, p. 30-33, D0I:10.1016/S0924-0136(02)00570-8.

[7] Jeswani, M.L. (1981). Effect of the addition of graphite powder to kerosene used as the dielectric fluid electrical discharge machining. Wear, vol. 70, p. 133-139, Dol:10.1016/00431648(81)90148-4.

[8] Uno, Y., Okada, A. (1997). Surface generation in electrical discharge machining with silicon powder mixed fluid. International Journal of Electrical Machining, vol. 2, no. 1, p. 13-18.

[9] Uno, Y., Okada, A., Cetin, S. (2001). Surface modification of EDMed surface with powder mixed fluid. $2^{\text {nd }}$ International Conference on Design and Production of Dies and Molds, $\mathrm{p}$. 86-92.

[10] Ming, Q.Y., He, L.Y. (1995). Powder-suspension dielectric fluid for EDM. Journal of Materials Processing Technology, vol. 52, no. 1-3, p. 44-54, D0I:10.1016/0924-0136(94)01442-4.

[11] Cogun, C., Ozerkan, H.B., Karacay, T. (2006). An experimental investigation on effect of powder mixed dielectric on machining performance in electric discharge machining (EDM). Proceedings of the Institution of Mechanical Engineers, Part B: Journal of Engineering Manufacture, vol. 14, no. 4, p. 202212 D0I:10.1243/09544054JEM320.

[12] Furutani, K., Saneto, A., Takezawa, H., Mohri, N., Miyake, H. (2001). Accretion of titanium carbide by electrical discharge machining with powder suspended in working fluid. Journal of the International Societies for Precision Engineering and Nanotechnology, vol. I, no. 25, p. 138-144, Dol:10.1016/ S0141-6359(00)00068-4.

[13] Prihandana, G.S., Sriani, T., Mahardika, M. (2012). Improvement of machining time in micro-EDM with workpiece vibration and graphite powder mixed in dielectric fluid. Indian Journal of Engineering and Materials Sciences, vol. 19, no. 6, p. 375-378.

[14] Reddy, V.V., Kumar, A., Valli, P.M., Reddy, C.S. (2015). Influence of surfactant and graphite powder concentration on electrical discharge machining of PH17-4 stainless steel. Journal of the Brazilian Society of Mechanical Science and Engineering, vol. 37, no. 2, p. 641-655, Dol:10.1007/s40430-014-0193-4.

[15] Lin, Y.C., Yan, B.H., Chang, Y.S. (2000). Machining characteristics of titanium alloy (Ti-6Al-4V) using a combination process of EDM with USM. Journal of Materials Processing Technology, vol. 104, no. 3, p. 171-177, Dol:10.1016/S09240136(00)00539-2.

[16] Chow, H.M., Yan, B.H., Huang, F.Y., Hung, J.C. (2000). Study of added powder in kerosene for the micro-slit machining of titanium alloy using electro-discharge machining. Journal of Materials Processing Technology, vol. 101, no. 1-3, p. 95-103, DOl:10.1016/S0924-0136(99)00458-6.

[17] Chow, H.M., Yan, L.D., Lin, C., Chen, C.F. (2008). The use of $\mathrm{SiC}$ powder in water as dielectric for micro-slit EDM Machining. Journal of Materials Processing Technology, vol. 195, no. 1-3, p. 160-170, DOI:10.1016/J.jmatprotec.2007.04.130.

[18] Rival, R. (2005). Electrical Discharge Machining of Titanium Alloy Using Copper Tungsten Electrode with SiC Powder Suspension Dielectric. MSc Thesis, University of Technology, Kuala Lumpur.

[19] Yasar, H., Ekmekci, B. (2014). Ti-6Al-4V surfaces in SiC mixed electric discharge machining. Advanced Materials Research, vol. 856 , p. 226-230, D0l:10.4028/www.scientific.net/ AMR.856.226. 
[20] Fonda, P., Wang, Z., Yamazaki, K., Akutsu, Y. (2008). A fundamental study on Ti-6Al-4V's thermal and electrical properties and their relation to EDM productivity. Journal of Materials Processing Technology, vol. 202, no. 1-3, p. 583589, D0I:10.1016/J.jmatprotec.2007.09.060.

[21] Cogun, C. (1990). A technique and its application for evaluation of materials contributions in electric discharge machining.
International Journal of Machine Tools and Manufacture, vol. 30, no. 1, p. 19-31, Dol:10.1016/0890-6955(90)90038-K.

[22] Ozgedik, A., Cogun, C. (2006). An experimental investigation on tool wear in electric discharge machining. International Journal of Advanced Manufacturing Technology, vol. 27, no. 5-6, p. 488-500, D0l:10.1007/s00170-004-2220-6. 